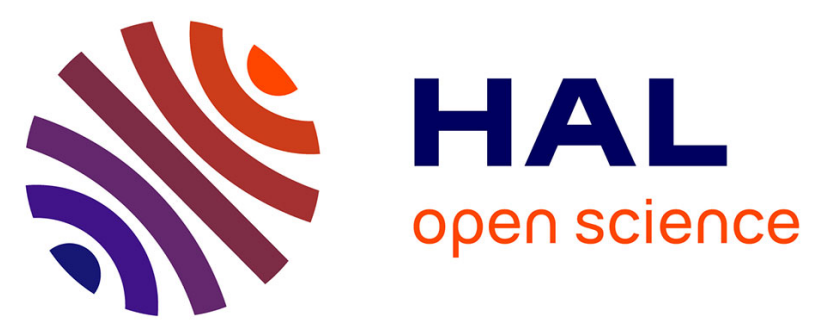

\title{
Combined Experimental/Theoretical Study on the Luminescent Properties of Homoleptic/Heteroleptic Erbium(III) Anilate-Based 2D Coordination Polymers
}

Suchithra Ashoka Sahadevan, Fabio Manna, Alexandre Abhervé, Mariangela

Oggianu, Noemi Monni, Valentina Mameli, Daniela Marongiu, Francesco

Quochi, Frédéric Gendron, Boris Le Guennic, et al.

\section{To cite this version:}

Suchithra Ashoka Sahadevan, Fabio Manna, Alexandre Abhervé, Mariangela Oggianu, Noemi Monni, et al.. Combined Experimental/Theoretical Study on the Luminescent Properties of Homoleptic/Heteroleptic Erbium(III) Anilate-Based 2D Coordination Polymers. Inorganic Chemistry, 2021, 60 (23), pp.17765-17774. 10.1021/acs.inorgchem.1c02386 . hal-03452303

\section{HAL Id: hal-03452303 \\ https://univ-angers.hal.science/hal-03452303}

Submitted on 26 Nov 2021

HAL is a multi-disciplinary open access archive for the deposit and dissemination of scientific research documents, whether they are published or not. The documents may come from teaching and research institutions in France or abroad, or from public or private research centers.
L'archive ouverte pluridisciplinaire HAL, est destinée au dépôt et à la diffusion de documents scientifiques de niveau recherche, publiés ou non, émanant des établissements d'enseignement et de recherche français ou étrangers, des laboratoires publics ou privés. 


\section{A Combined Experimental/Theoretical Study on the}

\section{Luminescent Properties of Homoleptic/Heteroleptic}

\section{ErIII/anilate-based 2D Coordination Polymers}

Suchithra Ashoka Sahadevan ${ }^{\dagger,}$, Fabio Manna ${ }^{\dagger}$ Alexandre Abhervé", Mariangela Oggianu ${ }^{\dagger, \partial}$, Noemi Monni ${ }^{\dagger, \partial}$, Valentina Mameli ${ }^{\dagger, \partial}$, Daniela Marongiu ${ }^{\delta}$, Francesco Quochi ${ }^{\delta, \partial}$, Frédéric

Gendron $^{*}$,Boris Le Guennic ${ }^{\star}$, Narcis Avarvari ${ }^{\prime} *$ and Maria Laura Mercuri ${ }^{\dagger}, \partial, *$

'Dipartimento di Scienze Chimiche e Geologiche, Università degli Studi di Cagliari, S.S. 554 Bivio per Sestu - I09042 Monserrato (Cagliari), Italy.

${ }^{\partial}$ Consorzio Interuniversitario Nazionale per La Scienza e Tecnologia Dei Materiali (INSTM), Cagliari Unit, Via Giuseppe Giusti 9, Firenze, 50121, Italy.

'Univ Angers, CNRS, MOLTECH-Anjou, SFR MATRIX, F-49000 Angers, France.

${ }^{\delta}$ Dipartimento di Fisica, Università degli Studi di Cagliari, I-09042 Monserrato Cagliari, Italy.

Univ Rennes, CNRS, ISCR (Institut des Sciences Chimiques de Rennes), UMR 6226, 35000 Rennes, France.

KEYWORDS. Anilates, Carboxylates, Erbium, 2D Coordination Polymers, Wave-Function Theory Analysis 


\section{ABSTRACT}

The synthesis, structural, photophysical characterization and theoretical studies on homo/heteroleptic neutral 2D layered coordination polymers (CPs), obtained by combining the erbium(III) ion with chlorocyananilates (ClCNAn) and/or tetrafluoroterephthalates ( $\left.\mathrm{F}_{4} \mathrm{BDC}\right)$ linkers, are herein reported. The structure of the heteroleptic $\mathrm{Er}^{\mathrm{III}}$-based CP, formulated as $\left[\mathrm{Er}_{2}(\mathrm{ClCNAn})_{2}\left(\mathrm{~F}_{4} \mathrm{BDC}\right)(\mathrm{DMSO})_{6}\right]_{\mathrm{n}}(\mathbf{1})$ is also reported. 1 crystallizes in the triclinic $P-1$ space group and the structure consists of neutral 2D layers formed by $\mathrm{Er}^{\mathrm{III}}$ ions linked through the two linkers oriented in such a way that the neighboring 2D layers are eclipsed along the $a$ axis, leading to parallelogram-like cavities. Photophysical measurements highlight the prominent role of chlorocyananilate linkers as optical antennas toward lanthanide ions, while wave-function theory analysis supports the experimental findings providing evidence for the effect of ligand substitution on the luminescence properties of homo/heteroleptic 2D CPs.

\section{INTRODUCTION}

Lanthanide Coordination Polymers (Ln-CPs) and Metal-Organic Frameworks (Ln-MOFs), built by self-assembling of $\mathrm{Ln}^{\mathrm{III}}$ metal ions and conjugated organic linkers, are extensively studied over the recent years because of their intriguing structural topologies, optical properties and several applications in various fields such as sensing, data storage, molecular spintronics and electronics, telecommunications, bioimaging, etc. ${ }^{1-4}$ By properly tailoring the coordination environment around the $\mathrm{Ln}^{\mathrm{III}}$ metal ions, through $i$ ) the various coordination modes of organic linkers and ii) a selection of linkers with high absorptivity, thus acting as suitable "antennas" for sensitizing 
lanthanide ions, interesting supramolecular frameworks, with peculiar luminescent properties 5,6 have been obtained. Some of the widely explored organic linkers behaving as valuable antennas are ligands with functional groups, such as pyridyl, carboxylate derivatives, $\beta$-diketonates, etc. ${ }^{6-11}$ A major drawback in the case of NIR-emitting complexes is the non-radiative deactivation due to C-H, N-H, O-H vibrations from ligands/solvents in the close vicinity to $\mathrm{Ln}^{\mathrm{III}}$ ions which significantly quenches the luminescence. To overcome this issue, fluorinated ligands are often used, which reduce fluorescence quenching effects of the overtones of $\mathrm{C}-\mathrm{H}$ vibrations by considering low-frequency C-F vibrations. ${ }^{12,13}$ In this context, 2,3,5,6-tetrafluoroterephthalic acid $\left(\mathrm{F}_{4} \mathrm{BDC}\right)$ is a valuable ligand for constructing multi-dimensional Ln-CPs, also for its versatile and multidentate coordination modes to lanthanide ions through carboxyl oxygen.$^{14,15}$ On the other hand, CPs based on 3,5-disubstituted-2,6-dihydroxy-1,4-benzoquinone, commonly called anilates, have been widely studied over the past decade. ${ }^{16-19}$ Anilates are excellent building blocks for constructing layered mono/multifunctional materials showing magnetic, ${ }^{20-25}$ conducting, ${ }^{26-29}$ and luminescent properties. ${ }^{30-32}$ Among them, the first example of heterosubstituted anilate, the chlorocyananilate ligand (3-chloro-6-cyano-2,5-dihydroxybenzoquinone- $\mathrm{ClCNAn}^{2-}$ ), is an interesting antenna linker for constructing Ln-CPs, due to the absence of IR quenchers in its molecular structure. ${ }^{33}$ The ability of ClCNAn ${ }^{2-}$ as antenna towards NIR emitting $\mathrm{Ln}^{\mathrm{III}}$ were studied by some of us in both bulk-sized 2D CPs, formulated as $\left[\operatorname{Ln}_{2}(\mathrm{ClCNAn})_{3}(\mathrm{DMF})_{6}\right]_{n} \cdot(\mathrm{DCM})_{x}[\mathrm{Ln}=$ $\mathrm{Yb}, \mathrm{Nd}$, and $\mathrm{Er}]$ and their related 2D ultrathin nanosheets obtained via solvent-assisted exfoliation methods by the top-down approach. ${ }^{30}$

A promising synthetic strategy to tune the structure and photophysical properties of Ln-CPs is the use of a suitable combination of mixed ligands ${ }^{34}$ to provide heteroleptic CPs, despite these mixed-ligands materials are scarcely studied, ${ }^{35}$ probably because of synthetic issues. The first 
ligand acts as an antenna to sensitize $\mathrm{Ln}^{\mathrm{III}}$ emission, while the second ligand would work as an ancillary bridging ligand for the construction of multi-dimensional networks. Very recently, some of us reported on the fabrication of robust and crystalline nanosheets of mixed-linkers (heteroleptic) 2D CPs based on $\mathrm{Yb}^{\mathrm{III}}$ and anilate/carboxylate derivatives, formulated as $\left[\mathrm{Yb}_{4}(\mathrm{ClCNAn})_{5}(\mathrm{DOBDC})_{1} \quad(\mathrm{DMSO})_{10}\right]_{\mathrm{n}} \cdot(\mathrm{DMSO})_{2}$ and $\quad\left[\mathrm{Yb}_{2}(\mathrm{ClCNAn})_{2}\left(\mathrm{~F}_{4} \mathrm{BDC}\right)(\mathrm{DMSO})_{6}\right]_{\mathrm{n}}$ (DOBDC $=2,5$-dihydroxybenzene-1,4-dicarboxylic acid), as innovative sensing nanoplatforms for nitroaromatics, paving the way to environmental sensing applications. ${ }^{31} \mathrm{~A} \mathrm{CP}$ built by the combination of mixed ligands, formulated as $\left.\mathrm{Nd}\left(\mathrm{F}_{4} \mathrm{BDC}\right)_{1.5}(\mathrm{phen})\left(\mathrm{H}_{2} \mathrm{O}\right)\right]_{\mathrm{n}}\left[\mathrm{F}_{4} \mathrm{BDC}-2,3,5,6-\right.$ tetrafluoroterephthalic acid; phen-1.10-phenanthroline] is also reported as sensor for detecting explosives such as cyclotetramethylene tetranitramine. ${ }^{36}$ In this material, both linkers contribute to the stability of the structure, due to the rigidity of ligands.

To the best of our knowledge, there are only a few heteroleptic CPs based on anilate/dicarboxylate ligands and NIR-emitting lanthanides. We report herein on the synthesis, structural characterization, and luminescent properties of a novel heteroleptic neutral 2D CP, formulated as $\left[\mathrm{Er}_{2}(\mathrm{ClCNAn})_{2}\left(\mathrm{~F}_{4} \mathrm{BDC}\right)(\mathrm{DMSO})_{6}\right]_{\mathrm{n}}$ (1) prepared by combining $\mathrm{Er}^{\mathrm{III}}$ ions with $\mathrm{ClCNAn} / \mathrm{F}_{4} \mathrm{BDC}$ linkers, via one-pot synthetic strategy. The role of the linkers in the sensitization and emission processes of Erbium(III) is studied spectroscopically and compared to previous findings on homoleptic $\mathrm{Yb}^{\mathrm{III}}$ and $\mathrm{Er}^{\mathrm{III}}$ chlorocyananilate-based 2D CPs. A theoretical study based on wave function theory (WFT) analysis is performed to gain deeper insights into the luminescent properties of the CPs and to shed light on the sensitization mechanism of the NIR emitting lanthanide ions. 


\section{RESULTS AND DISCUSSION}

2.1. Synthesis and crystal structure. $\left[\mathrm{Er}_{2}(\mathrm{ClCNAn})_{2}\left(\mathrm{~F}_{4} \mathrm{BDC}\right)(\mathrm{DMSO})_{6}\right]_{\mathrm{n}}(\mathbf{1})$ is formed by combining $\mathrm{Er}^{\mathrm{III}}$ salt with both linkers $\mathrm{ClCNAn}^{2-}$ and $\mathrm{F}_{4} \mathrm{BDC}^{2-}$, by an one-pot synthetic reaction in water. The obtained red solid is recrystallized in DMSO affording, after several weeks, red single crystals suitable for X-ray analysis. The synthesis of 2D hetero/homoleptic CPs with $\mathrm{Ln}^{\mathrm{III}}=\mathrm{Er}$ and $\mathrm{Yb}$, discussed in the text, is shown in Scheme 1. The molecular structure and luminescent properties of homoleptic and the $\mathrm{Yb}$-heteroleptic $\mathrm{CPs}$ were already reported in refs [30,31].

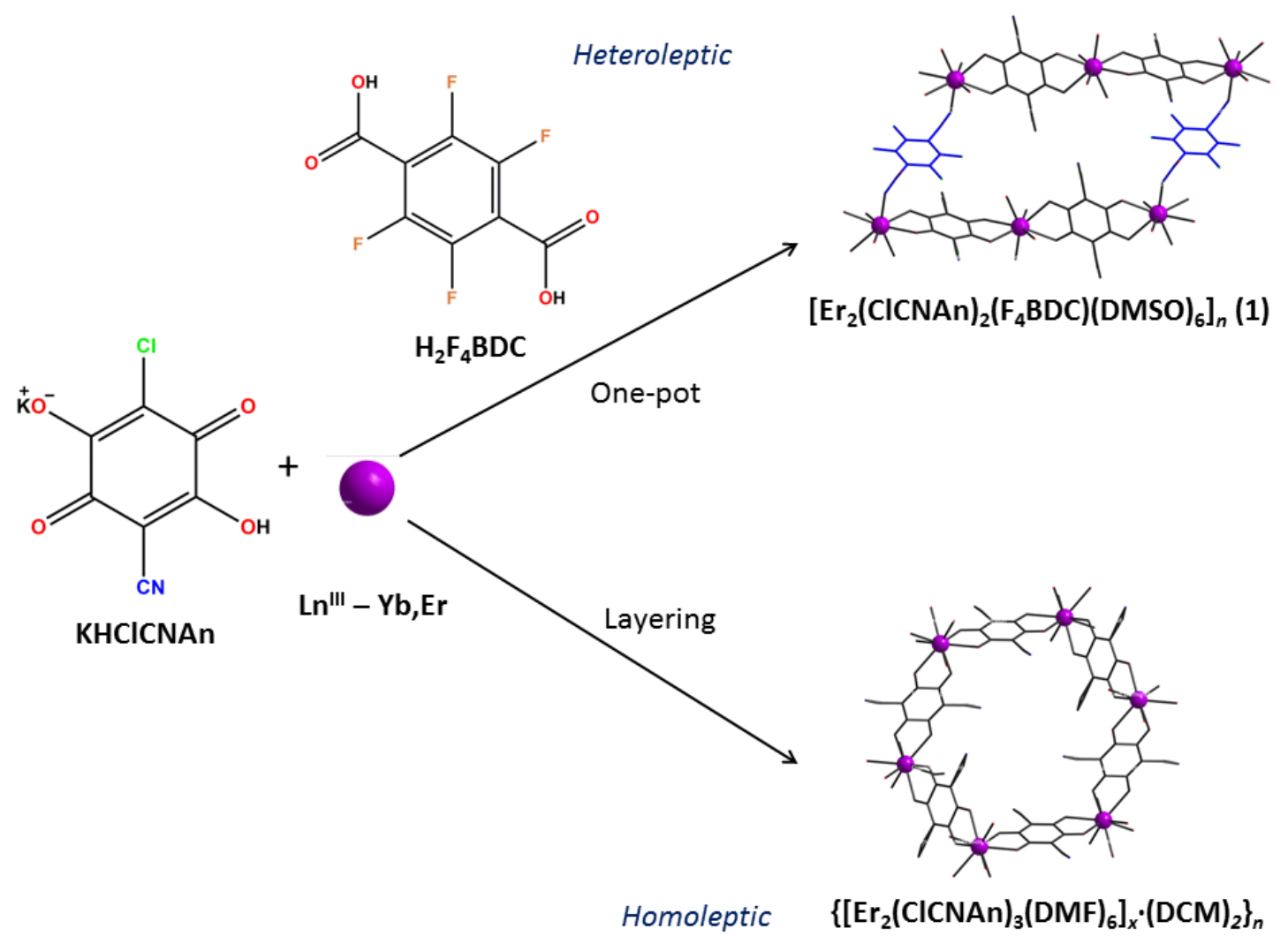

Scheme 1. General synthetic procedure for the synthesis of hetero/homoleptic compounds. The $\mathrm{F}_{4} \mathrm{BDC}^{2-}$ linker in the heteroleptic compound is highlighted in blue. 
Single crystal X-ray analysis reveals that 1 crystallizes in the triclinic $P-1$ space group. In the structure, the $\mathrm{Er}^{\mathrm{III}}$ ions are connected through mixed linkers $\mathrm{ClCNAn}^{2-}$ and $\mathrm{F}_{4} \mathrm{BDC}^{2-}$, leading to a 2D neutral layered CP. The asymmetric unit consists of one $\mathrm{Er}^{\mathrm{III}}$ ion, two half molecules of $\mathrm{ClCNAn}^{2-}$, one-half molecule of $\mathrm{F}_{4} \mathrm{BDC}$ and three molecules of DMSO. As generally seen in ClCNAn-based $\mathrm{CPs}^{21,30,31,37}$, chloro- and cyano-substituents are disordered and occupy two positions with an occupancy factor of 0.5 each. The two ligands exhibit different coordination modes around the metal ion, where $\mathrm{ClCNAn}{ }^{2-}$ is coordinated to the $\mathrm{Er}^{\mathrm{III}}$ ions in the usual bidentate mode, whereas $\mathrm{F}_{4} \mathrm{BDC}^{2-}$ coordinates in a monodentate manner.

Each erbium ion is eight coordinated by four oxygens from $\mathrm{ClCNAn}^{2-}$, one oxygen from $\mathrm{F}_{4} \mathrm{BDC}^{2-}$ and three oxygens from coordinated DMSO solvent molecule (Figure 1a), forming a $\mathrm{ErO}_{8}$ polyhedron with distorted trigonal dodecahedron geometry (Figure S1). Er-O bond distances and O-Er-O bond angles range between 2.218(2) - 2.431(2) $\AA$ and 65.54(8) - 145.29(8) ${ }^{\circ}$, respectively. As shown in Figure 1b, ClCNAn ${ }^{2-}$ ligands bridge two $\mathrm{Er}^{\mathrm{III}}$ ion in a bis-1,2-bidentate manner forming a $1 \mathrm{D}$ chain along the $c$ axis. The second ligand, $\mathrm{F}_{4} \mathrm{BDC}^{2-}$, acts as a bridge between neighboring $1 \mathrm{D}$ chains, thus leading to 2D layers. The neighboring 2D layers are eclipsed in the $b c$ plane forming parallelogram-like cavities. In the $a c$ plane, 2D layers are arranged in a wavelike manner (Figure 1c). A similar structure was reported for the homologous heteroleptic CP with the $\mathrm{Yb}^{\mathrm{III}}$ ion. ${ }^{31}$ 


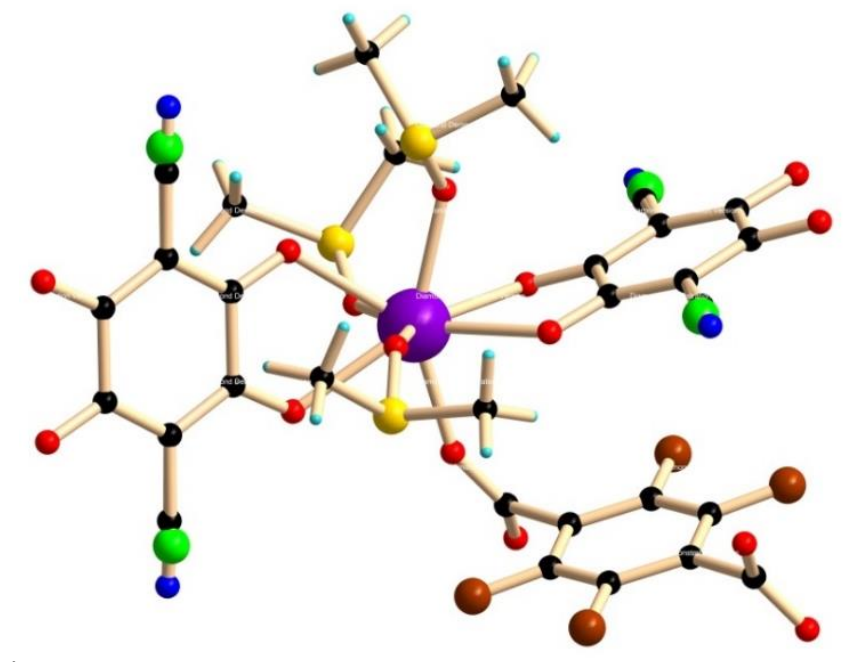

(a)

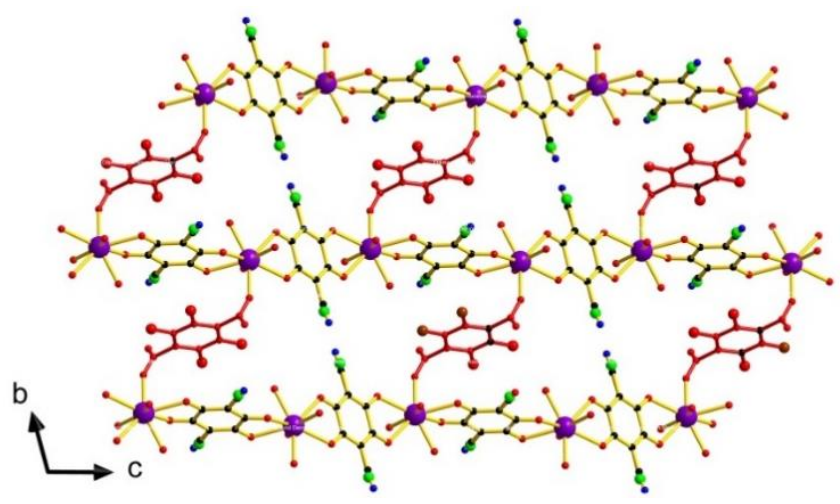

(b)

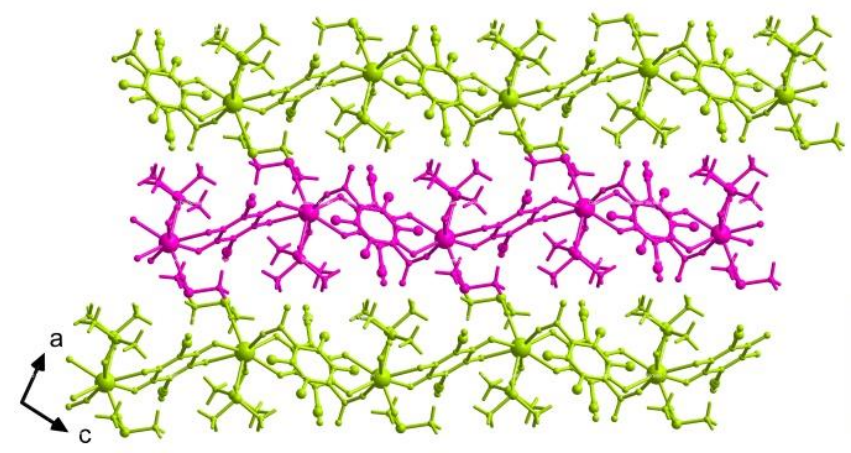

(c)

Figure 1. a) Coordination environment around $\mathrm{Er}^{\mathrm{III}}$ metal ion. b) View of the 2D layers in the $b c$ plane, highlighting second ligand in red. c) View of the 2D layers in the ac plane, neighboring layers are shown in different colors. Color code: $\mathrm{Er}=$ purple, $\mathrm{S}=$ yellow, $\mathrm{O}=$ red, $\mathrm{Cl}=$ green, $\mathrm{F}=$ brown, $\mathrm{C}=$ black, $\mathrm{N}=$ blue and $\mathrm{H}=$ cyan. 


\subsection{Photophysical Studies.}

Finely ground crystals of freshly prepared 1 were studied by continuous wave (cw) absorption spectroscopy and photoluminescence (PL) spectroscopy under pulsed laser irradiance in a weak excitation regime where the response of $\mathbf{1}$ is linear in the irradiance over a wide range. The results of the optical and photophysical studies are summarized in Figure 2.
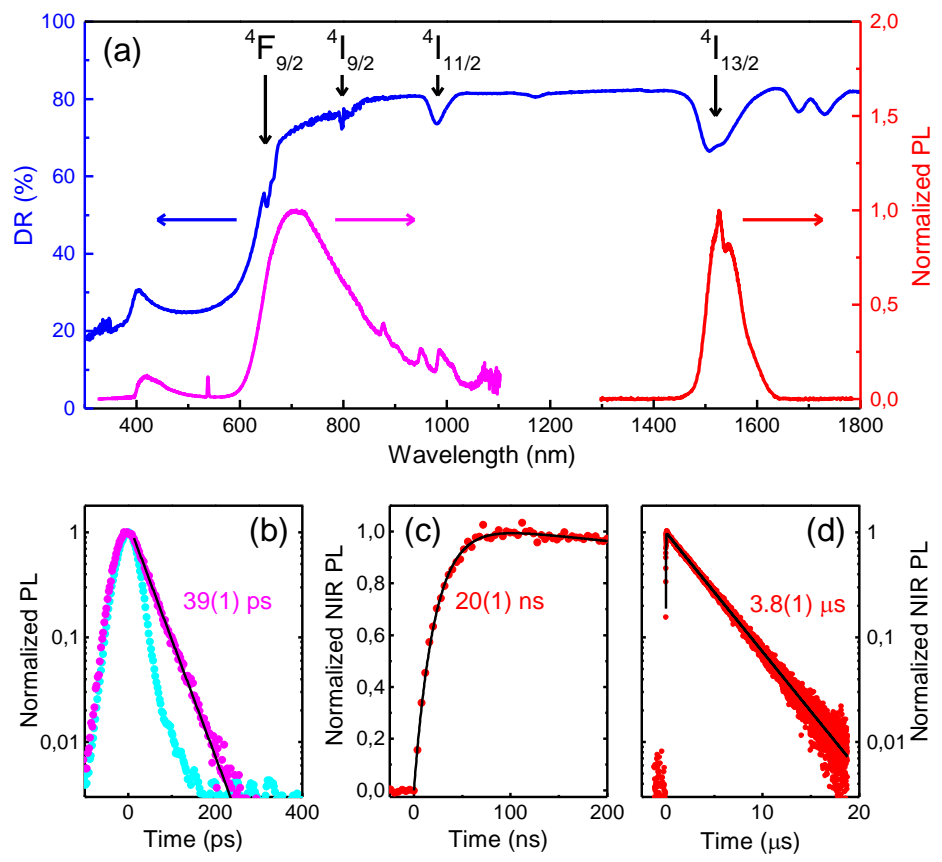

Figure 2. Optical and photophysical measurements on crystals of 1. (a) Diffuse reflectance (DR) spectrum (blue line, left scale) and photoluminescence (PL) spectra across visible and NIR ranges under pulsed laser irradiance at $355 \mathrm{~nm}$ (magenta and red lines, right scale). Spectroscopic terms of upper states of $\mathrm{Er}^{\mathrm{III}}$ absorption transitions are indicated. (b) Magenta dots: Time-resolved PL integrated over the ligand-centered band peaked at $\sim 700 \mathrm{~nm}$, showing the ligand excited-state decay; Black line: Best fit of a monoexponential decay curve to data. The cyan dots depict the impulse response function of the detection system. (c) Red dots: Time-resolved NIR PL integrated over the Er ${ }^{\mathrm{III}}$ emission band peaked at $1530 \mathrm{~nm}$, highlighting the lanthanide sensitization process. (d) Same as in (c) but on a much longer time range to display the lanthanide emission decay. Black lines in (c,d) represent the best fit of a two-component exponential function, modelling $\mathrm{Er}^{\mathrm{III}}$ sensitization and decay kinetics, to data (see text for details). Sensitization and decay time constants are also shown in (b-d). 
The diffuse reflectance (DR) spectrum, acquired over a broad spectral range spanning through the visible and the NIR, shows evidence of both ligands- and $\mathrm{Er}^{\mathrm{III}}$-centered absorption processes (Figure 2a). The absorption band in the visible clearly resembles that of the homoleptic $\operatorname{Er}(\mathrm{Yb})$ ClCNAn CPs reported previously ${ }^{30}$ and is thus ascribed to the ClCNAn ${ }^{2-}$ linkers. In the near UV portion of the spectrum, below $400 \mathrm{~nm}$ wavelength, the $\mathrm{F}_{4} \mathrm{BDC}^{2-}$ ligands are expected to give a minority contribution to the optical absorption of $1 .^{31}$ Dips observed between 1600 and $1800 \mathrm{~nm}$ were assigned to water absorption. PL spectra acquired separately in the 400-1100 nm and 1300$1800 \mathrm{~nm}$ wavelength ranges are in fact greatly complementary to the DR one (Figure 2a), making it easy to single out ligand- $\left(\mathrm{ClCNAn}^{2-}\right)$-centered and $\mathrm{Er}^{\mathrm{III}}$-centered PL components. The emission band extending from 400 to $500 \mathrm{~nm}$ represents a background emission from the quartz substrates (see Experimental Section), hence $\mathrm{F}_{4} \mathrm{BDC}^{2-}$ linkers appeared to be optically inactive overall, in line with their designed function as ancillary bridging units. Narrow peaks located at $~ 540, \sim 880$, and $\sim 950 \mathrm{~nm}$ in the emission spectrum could not be identified and were attributed to residual room light.

As shown in Figure 2b, the ligand-centered emission triggered by the pulsed pump laser exhibits a fast monoexponential decay kinetics with a characteristic time of $\sim 40 \mathrm{ps,} \mathrm{which} \mathrm{is} \mathrm{in} \mathrm{fact} \mathrm{close}$ to the temporal resolution of the experiment. Owing to the $\sim 200 \mathrm{ps}$ PL lifetime of the ClCNAn ${ }^{2-}$ anion in the KHClCNAn salt, a strong excited-state relaxation channel was inferred to result from ligand coordination to $\mathrm{Er}^{\mathrm{III}}$. This was identified as lanthanide-enhanced intersystem (singlet-totriplet) crossing (ISC), which, following ligand-centered optical absorption, initiates the overall antenna effect ending up with lanthanide sensitization.

The Er ${ }^{I I I}$-centered $\left({ }^{4} \mathrm{I}_{13 / 2} \rightarrow{ }^{4} \mathrm{I}_{15 / 2}\right)$ emission band peaked at $\sim 1530 \mathrm{~nm}$ was found to rise in the time scale of a few tens of nanoseconds and decay in a few microseconds (Figure 2c, d). Curve fitting 
to the PL temporal profile was applied using a monoexponential rise and monoexponential decay function as follows:

$$
I_{\mathrm{Er}}(t)=A\left[\exp \left(-t / \tau_{\mathrm{D}}\right)-\exp \left(-t / \tau_{\mathrm{S}}\right)\right]=A\left[1-\exp \left(-t / \tau_{\mathrm{R}}\right)\right] \exp \left(-t / \tau_{\mathrm{D}}\right),
$$

where $A$ is a signal amplitude, $\tau_{\mathrm{S}}, \tau_{\mathrm{R}}$ and $\tau_{\mathrm{D}}$ are the $\operatorname{Er}{ }^{\mathrm{III}}\left({ }^{4} \mathrm{I}_{13 / 2}\right)$ sensitization, rise and decay time constants, respectively $\left(\tau_{\mathrm{R}}^{-1}=\tau_{\mathrm{S}}^{-1}-\tau_{\mathrm{D}}^{-1}\right)$. Curve fitting yielded $\tau_{\mathrm{S}}=20(1) \mathrm{ns}$ and $\tau_{\mathrm{D}}=3.8(1)$ $\mu$ s. As the Er ${ }^{\mathrm{III}}$-centered emission sensitization process is much slower than ClCNAn ${ }^{2-}$-centered emission decay, cascaded energy relaxation from the ClCNAn ${ }^{2-}$ linkers to the $\mathrm{Er}^{\mathrm{III}}$ ions through ISC and ligand-to-metal energy transfer is postulated to take place in $\mathbf{1} .^{30,31}$

Photophysical parameters of $\mathbf{1}$ and related compounds previously studied ${ }^{30,31}$ are summarized in Table 1.

Table 1. Ligand-centered PL decay time $\left(\tau_{\mathrm{L}}\right), \mathrm{Ln}^{\mathrm{III}}$-centered PL sensitization time $\left(\tau_{\mathrm{S}}\right)$, and $\mathrm{Ln}^{\mathrm{III}}$-centered PL decay time $\left(\tau_{\mathrm{D}}\right)$ of 1 and compounds investigated in previous work ${ }^{30,31}$

\begin{tabular}{|c|c|c|c|c|}
\hline Compound & Reference & $\tau_{\mathrm{L}}(\mathrm{ps})$ & $\tau_{\mathrm{S}}(\mathrm{ns})$ & $\tau_{\mathrm{D}}(\mu \mathrm{s})$ \\
\hline$\left[\mathrm{Er}_{2}(\mathrm{ClCNAn})_{2}\left(\mathrm{~F}_{4} \mathrm{BDC}\right)(\mathrm{DMSO})_{6}\right]_{\mathrm{n}}(\mathbf{1})$ & this Work & 39 & 20 & 3.8 \\
\hline$\left\{\left[\mathrm{Er}_{2}(\mathrm{ClCNAn})_{3}(\mathrm{DMF})_{6}\right](\mathrm{DCM})_{2}\right\}_{\mathrm{n}}$ & 30 & 42 & 16 & 2.1 \\
\hline$\left[\mathrm{Yb}_{2}(\mathrm{ClCNAn})_{3}(\mathrm{DMF})_{6}\right]_{\mathrm{n}}$ & 30 & $\sim 30$ & $<1$ & 8.6 \\
\hline$\left[\mathrm{Yb}_{4}(\mathrm{ClCNAn})_{5}(\mathrm{DOBDC})(\mathrm{DMSO})_{10}\right]_{\mathrm{n}} \cdot(\mathrm{DMSO})_{2}$ & 31 & $<30$ & $<1$ & 10 \\
\hline$\left[\mathrm{Yb}_{2}(\mathrm{ClCNAn})_{2}(\mathrm{~F} 4 \mathrm{BDC})(\mathrm{DMSO})_{6}\right]_{\mathrm{n}}$ & 31 & $<30$ & $<1$ & 3.8 \\
\hline
\end{tabular}

Noticeably, the observed Er ${ }^{\mathrm{III}}$ NIR PL lifetime of $3.8 \mu \mathrm{s}$ is almost twice as long as that of the corresponding homoleptic Er-ClCNAn CP $(2.1 \mu \mathrm{s}),{ }^{30}$ hinting to a possibly reduced vibrational quenching of the Er ${ }^{\mathrm{III}}$ NIR emission in 1. As a matter of fact, the first coordination sphere of $\mathrm{Er}^{\mathrm{III}}$ 
in the homoleptic $\mathrm{CP}$ contains three DMF ligand molecules, bearing six $-\mathrm{CH}_{3}$ groups and three $-\mathrm{CH}$ groups in total, whereas in $\mathbf{1}$ the three coordinated DMSO molecules contribute with only six $-\mathrm{CH}_{3}$ groups. The same qualitative considerations should in principle apply also to the $\mathrm{Yb}-$ based CPs. In $\left[\mathrm{Yb}_{4}(\mathrm{ClCNAn})_{5}(\mathrm{DOBDC})(\mathrm{DMSO})_{10}\right]_{\mathrm{n}} \cdot(\mathrm{DMSO})_{2}$, where the $\mathrm{Yb}^{\mathrm{III}}$ coordination environment comprises on average five $-\mathrm{CH}_{3}$ groups, one $-\mathrm{CH}$ group and one $-\mathrm{OH}$ group, a moderate increase in NIR PL lifetime was in fact reported with respect to the $\left[\mathrm{Yb}_{2}(\mathrm{ClCNAn})_{3}(\mathrm{DMF})_{6}\right]_{\mathrm{n}}$ case. A corresponding improvement in the NIR PL lifetime of $\left.\mathrm{Yb}_{2}(\mathrm{ClCNAn})_{2}\left(\mathrm{~F}_{4} \mathrm{BDC}\right)(\mathrm{DMSO})_{6}\right]_{\mathrm{n}}$ could however not be assessed, presumably due to a high sensitivity of crystals of the $\mathrm{F}_{4} \mathrm{BDC}$-containing $\mathrm{CP}$ to ambient conditions, actually resulting in a shorter lifetime.

\subsection{Wave-function Theory (WFT) Analysis.}

In order to rationalize the luminescence properties of the investigated complexes, multi-reference WFT calculations were performed on homoleptic CPs, $\left[\mathbf{Y b}(\mathbf{C I C N A n})_{3}\right]^{3-}$ and $\left[\operatorname{Er}(\operatorname{CICNAn})_{3}\right]^{3-}$, previously described, ${ }^{30}$ and the heteroleptic $\left[\operatorname{Er}(\mathbf{C I C N A n})_{2}\left(\mathbf{F}_{4} \mathbf{B D C}\right)\right]^{3-} \mathbf{1}$ as model compounds

(Figure 3, see computational details). The calculated energy state diagrams at the RASSCF level for these model compounds are shown in Figure 4 and 5, while the numerical values used for these diagrams are collected in Tables S1-S3. 


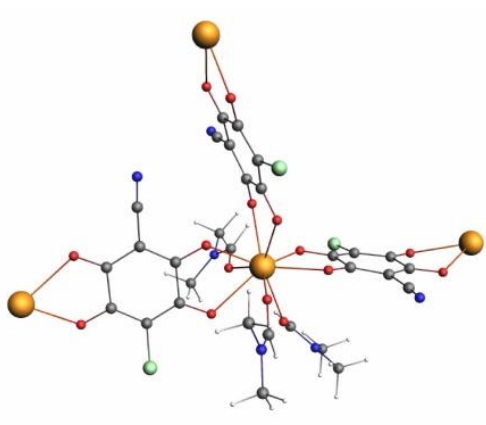

a

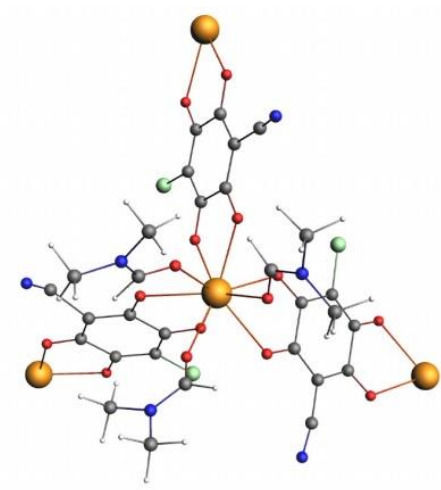

b

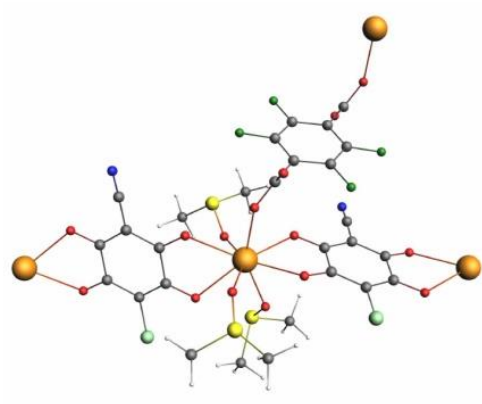

$\mathrm{c}$

Figure 3. Representation of the model compounds $\left[\operatorname{Yb}(\mathbf{C I C N A n})_{3}\right]^{3-}$ (a), $\left[\operatorname{Er}(\mathbf{C l C N A n})_{3}\right]^{3-}$ (b), and $\left[\operatorname{Er}(\mathrm{CICNAn})_{2}\left(\mathrm{~F}_{4} \mathrm{BDC}\right)\right]^{3-}(\mathrm{c})$.

At the spin-free (SF) level (i.e. without spin-orbit coupling), the excited ligand-centered singlet states S1 are calculated at $636\left(15711 \mathrm{~cm}^{-1}\right)$ and $646 \mathrm{~nm}\left(15483 \mathrm{~cm}^{-1}\right)$ in $\left[\mathbf{Y b}(\mathbf{C I C N A n})_{3}\right]^{3-}$ and $\left[\operatorname{Er}(\mathbf{C I C N A n})_{3}\right]^{3-}$, respectively, and compare very well with the experimental data of ca. $650 \mathrm{~nm}$. As illustrated by the natural orbitals (NOs) in Figures S2 and S3, this first singlet excited state corresponds to a $\pi-\pi^{*}$ excitation within the anilate ligands. In $\left[\mathbf{Y b}(\mathbf{C I C N A n})_{3}\right]^{3-}$, the lowest ligandcentered triplet state T1 is located below in energy than the $\mathrm{S} 1$ state $\left(15297 \mathrm{vs} .15711 \mathrm{~cm}^{-1}\right)$, while it is calculated at similar energy than the $\mathrm{S} 1$ state in the $\mathrm{Er}^{\mathrm{III}}$ analogue compound (15577 vs. 15483 $\left.\mathrm{cm}^{-1}\right)$. Therefore, the calculated gap $\Delta \mathrm{E}_{(\mathrm{S} 1-\mathrm{T} 1)}$ at the RASSCF level are of 414 and $94 \mathrm{~cm}^{-1}$ in the $\mathrm{Yb}^{\mathrm{III}}$ and $\mathrm{Er}^{\mathrm{III}}$ tris-anilate model compounds, respectively, favoring a strong inter-system crossing between these states in both complexes.

As visible in Tables $\mathrm{S} 1$ and $\mathrm{S} 2$, the introduction of the spin-orbit (SO) coupling leads to a large admixture of the ligand-centered singlet and triplet states into the Kramers doublet (KD) states, which are labeled as the ISC area in Figures 4 and 5. Interestingly, in $\left[\mathbf{Y b}(\mathbf{C l C N A n})_{3}\right]^{3-}$ a set of three KD states arising mainly from the SF triplet spin states are calculated below the ISC area, 
and can thus participate to non-radiative relaxation processes. In both the $\mathrm{Yb}^{\mathrm{III}}$ and $\mathrm{Er}^{\mathrm{III}}$ tris-anilate model compounds, the ligand-centered KDs are located above the lanthanide emissive states. In $\left[\operatorname{Yb}(\mathbf{C I C N A n})_{3}\right]^{3-}$, an energy gap of ca. $4500 \mathrm{~cm}^{-1}$ is calculated between the lowest $\mathrm{KD}$ states centered on the anilate ligands and the emissive $\mathrm{KDs}$ of the ${ }^{2} \mathrm{~F}_{5 / 2}$ level, allowing efficient energy transfer. In agreement with the experimental data $\left(\lambda_{\mathrm{ems}} \approx 980 \mathrm{~nm}\right)$, the three emissive KDs are calculated 10318, 10583 and $10784 \mathrm{~cm}^{-1}$. In $\left[\operatorname{Er}(\mathbf{C l C N A n})_{3}\right]^{3-}$, the lowest ligand-centered KD (KD22) is located at ca. $4000 \mathrm{~cm}^{-1}$ above the Erbium(III) centered excited states of the ${ }^{4} \mathrm{I}_{11 / 2}$ level. Here, the emissive KDs of the ${ }^{4} \mathrm{I}_{13 / 2}$ level are calculated between 6148 and $6276 \mathrm{~cm}^{-1}$, slightly lower in energy than the experimental observation $\left(\lambda_{\text {ems }} \approx 1500-1570 \mathrm{~nm}\right)$.
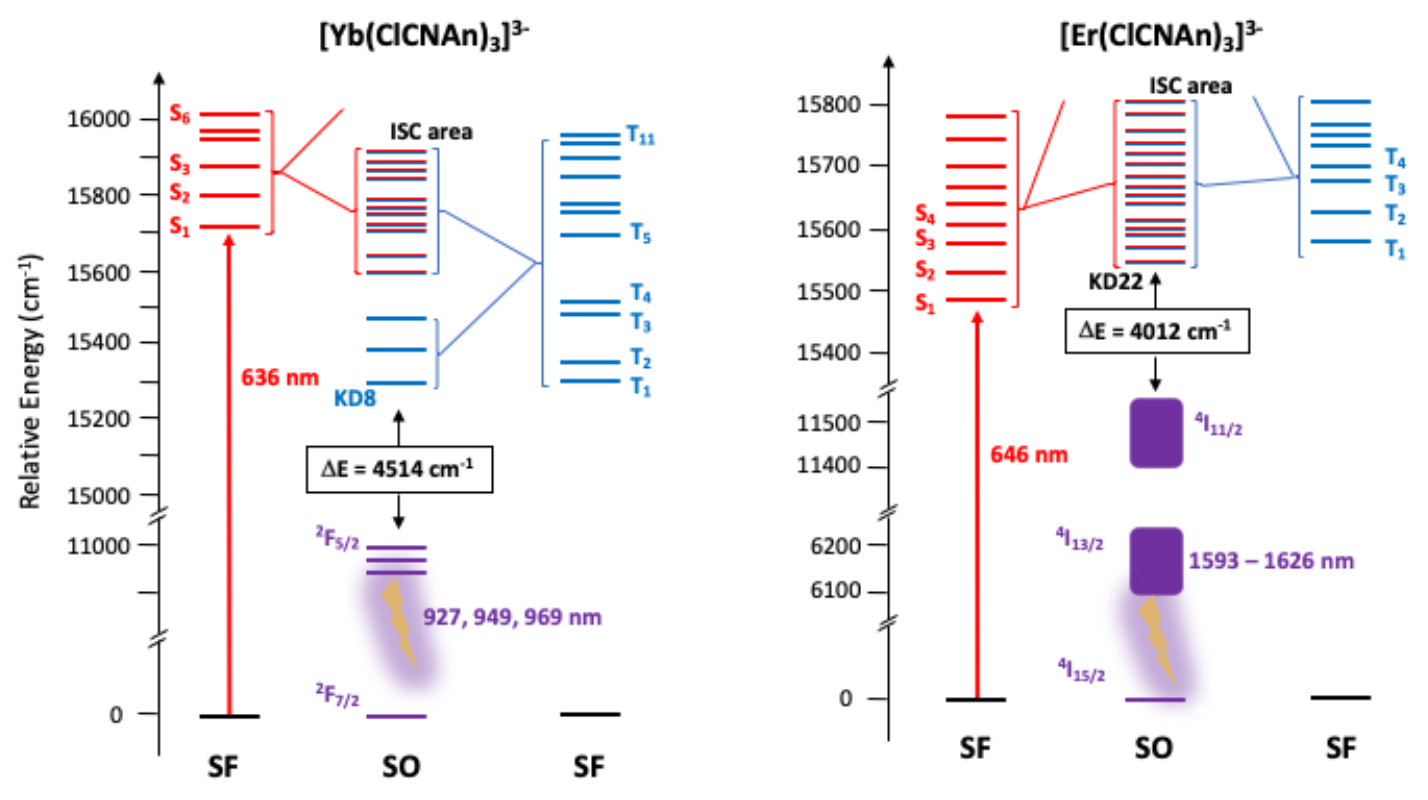

Figure 4. Calculated energy state diagrams $\left(\right.$ in $\left.\mathrm{cm}^{-1}\right)$ of $\left[\operatorname{Yb}(\mathbf{C I C N A n})_{3}\right]^{3-}($ left $),\left[\operatorname{Er}(\operatorname{ClCNAn})_{3}\right]^{3-}$ (right). Mind the change in the energy scale between the two state diagrams.

The influence of the substitution of one anilate ligand by a tetrafluoroterephthalate ligand in $\left[\operatorname{Er}(\mathbf{C l C N A n})_{2}\left(\mathbf{F}_{4} \mathbf{B D C}\right)\right]^{3-}$ is shown in Figure 5 with the calculated state diagram. At the spin-free level, the comparison between the two state diagrams reveals a sizeable energetic stabilization of 
the S1 $\left(311 \mathrm{~cm}^{-1}\right)$ and $\mathrm{T} 1\left(634 \mathrm{~cm}^{-1}\right)$ states in $\left[\mathbf{E r}(\mathbf{C l C N A n})_{2}\left(\mathbf{F}_{4} \mathbf{B D C}\right)\right]^{3-}$. This energetic stabilization of the lowest singlet and triplet states could arise from the ligand substitution, but could also result from the difference in the choice of the active space and the number of roots included in the state-average calculations (see computational details), and thus prevents from a clear conclusion. Nevertheless, at the spin-orbit level, the ligand substitution barely influences the energy of the $\mathrm{Er}^{\mathrm{III}}$ centered-states. For instance, the emissive states from the ${ }^{4} \mathrm{I}_{13 / 2}$ level are calculated between 6118 and $6316 \mathrm{~cm}^{-1}$ above the GS in $\left[\operatorname{Er}(\mathbf{C I C N A n})_{2}\left(\mathbf{F}_{4} \mathbf{B D C}\right)\right]^{3-}$, while the corresponding states in the tri-anilate compound were calculated between 6148 and $6276 \mathrm{~cm}^{-1}$. Due to the energetic stabilization of the SF singlet and triplet states, the lowest ligand-centered $\mathrm{KD}$ in $\left[\operatorname{Er}(\mathbf{C I C N A n})_{2}\left(\mathbf{F}_{4} \mathbf{B D C}\right)\right]^{3-}$ is marginally closer in energy to the $\mathrm{Er}^{\mathrm{III}}$-centered ${ }^{4} \mathrm{I}_{11 / 2}$ level $\left(\Delta E=3383 \mathrm{~cm}^{-1}\right)$ than in the tris-anilate analogue $\left(\Delta E=4012 \mathrm{~cm}^{-1}\right)$.
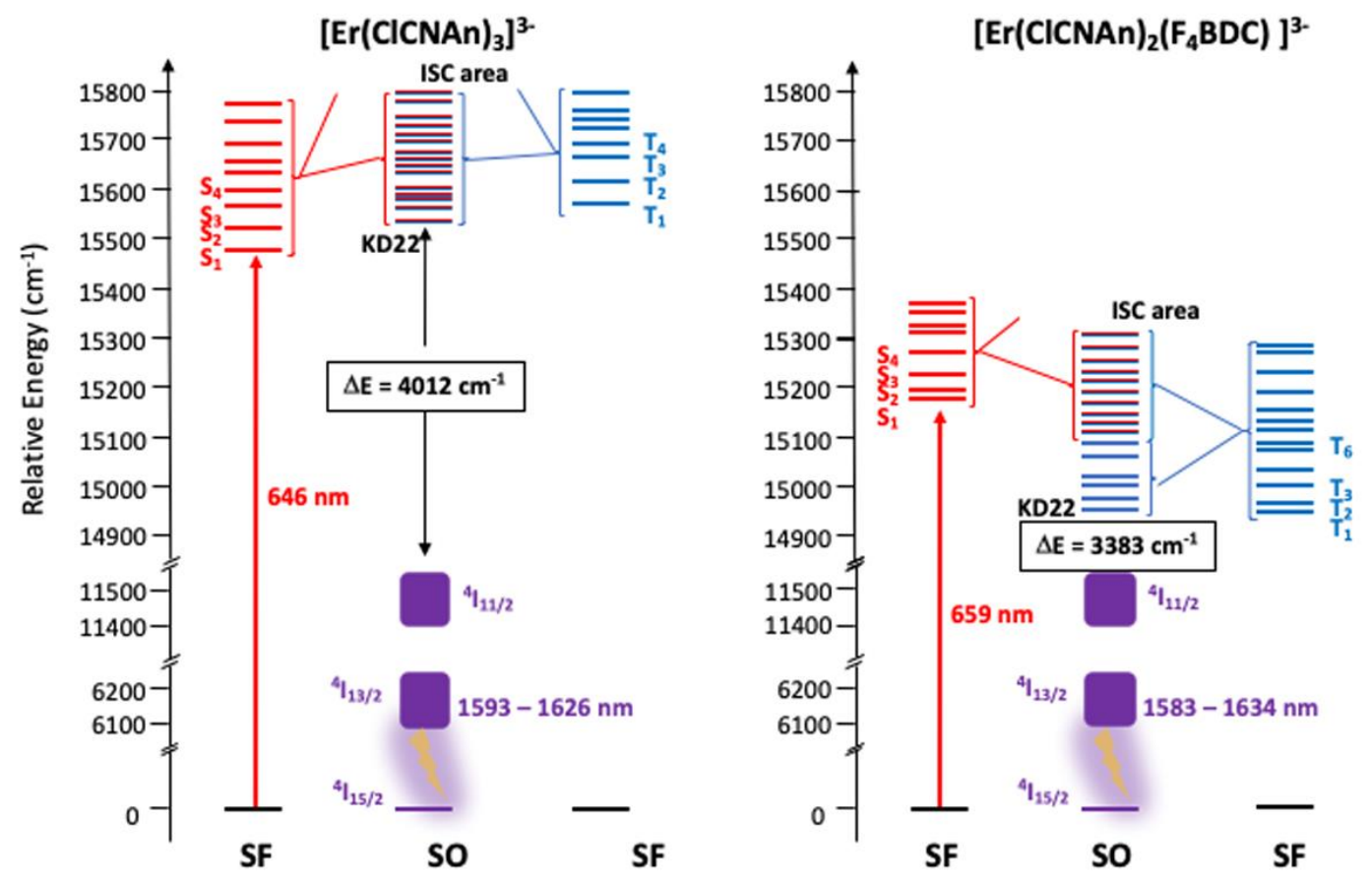

Figure 5. Calculated energy state diagrams $\left(\right.$ in $\left.\mathrm{cm}^{-1}\right)$ of $\left[\operatorname{Er}(\mathbf{C l C N A n})_{3}\right]^{3-}($ left $),\left[\operatorname{Er}(\mathbf{C I C N A n})_{2}\left(\mathbf{F}_{4} \mathbf{B D C}^{3-}\right]^{3-}(\right.$ right $)$. 
Through this theoretical study the efficient antenna effect of the chlorocyananilate ligand in the sensitization of NIR emissive lanthanide complexes thanks to efficient energy transfer from Kramer doublet states is thus clearly demonstrated for the first time.

\section{CONCLUSIONS}

A combined experimental/theoretical study on the luminescent properties of homoleptic/heteroleptic Er ${ }^{\mathrm{III}} /$ anilate-based 2D CPs is herein reported. The heteroleptic 2D neutral $\mathrm{CP}$, formulated as $\left[\mathrm{Er}_{2}(\mathrm{ClCNAn})_{2}\left(\mathrm{~F}_{4} \mathrm{BDC}\right)(\mathrm{DMSO})_{6}\right]_{\mathrm{n}}(\mathbf{1})$, has been synthesized by combining $\mathrm{Er}^{\mathrm{III}}$ ions with $\mathrm{ClCNAn}^{2-} / \mathrm{F}_{4} \mathrm{BDC}^{2-}$ linkers, via one-pot synthetic strategy, and structurally characterized. Photophysical measurements emphasized the role of chlorocyananilate linker as optical antenna toward Erbium(III) ions, as already observed in previously reported 2D neutral homoleptic $\mathrm{Yb}^{\mathrm{III}}$ and $\mathrm{Er}^{\mathrm{III}} \mathrm{CPs}$. The remarkable increase observed in the $\mathrm{Er}^{\mathrm{III}}$ NIR PL lifetime (3.8 $\mu \mathrm{s})$, which was attributed to a reduced vibrational quenching, points out the beneficial effect of the fully fluorinated $\mathrm{F}_{4} \mathrm{BDC}^{2-}$ linker on the NIR emission efficiency of $\mathrm{Er}^{\mathrm{III}}$. Wave-Function Theory calculations demonstrate the dominant role of the chlorocyananilate linker as optical antenna responsible for $\mathrm{Er}^{\mathrm{III}} \mathrm{NIR}$ luminescence sensitization, through an efficient energy transfer from Kramer doublet states. Noteworthy, this theoretical approach can provide guidelines for a rational design of Ln-CPs with efficient NIR emission, which can be modulated by a proper selection of ligand admixture. It is also worth mentioning that $\mathrm{Ln}^{\mathrm{III}}$-based molecular materials have been increasingly considered in recent years for potential bio-applications using up-conversion luminescence processes. ${ }^{38,39}$ In the specific case of $\mathrm{Er}^{\mathrm{III}}$-based materials such as $\mathrm{Er}^{\mathrm{III}} \mathrm{CPs}$, green up-conversion luminescence for, e.g., bioimaging and photodynamic therapy applications can be generated by $\mathrm{Er}^{\mathrm{III}}$ direct photoexcitation using a convenient $\mathrm{cw}$ laser diode at $980 \mathrm{~nm}$ wavelength, 
in the optical transparency window where the light penetration depth in the biological tissues can be of several centimeters.

\section{EXPERIMENTAL SECTION}

4.1. Materials and Methods. Reagents of analytical grade were purchased from Zentek (TCI) and used without further purification. The HPLC grade solvents were purchased from Thermofisher

Scientific Alfa-Aesar. KHClCNAn was synthesized as reported in the literature, ${ }^{33}$ while $\operatorname{Er}\left(\mathrm{NO}_{3}\right)_{3}$ $\cdot 5 \mathrm{H}_{2} \mathrm{O}$ and $\mathrm{H}_{2} \mathrm{~F}_{4} \mathrm{BDC}$ were purchased from Thermofisher Scientific Alfa-Aesar and used without further purification.

4.2. Synthesis. $\left[\mathrm{Er}_{2}(\mathrm{ClCNAn})_{2}\left(\mathrm{~F}_{4} \mathrm{BDC}\right)(\mathrm{DMSO})_{6}\right]_{\mathrm{n}}:$ The compound was synthesized by adapting our procedure ${ }^{31}$ by using $\mathrm{Er}\left(\mathrm{NO}_{3}\right)_{3} \cdot 5 \mathrm{H}_{2} \mathrm{O}(230 \mathrm{mg}, 0.6 \mathrm{mmol})$ instead of $\mathrm{YbCl}_{3} \cdot 5 \mathrm{H}_{2} \mathrm{O}$.

4.3. X-ray Crystallography. Single crystals of the compound were mounted on glass fiber loops using a viscous hydrocarbon oil to coat the crystal and then transferred directly to the cold nitrogen stream for data collection. Data collection was performed at $150 \mathrm{~K}$ on an Agilent Supernova with $\mathrm{CuK} \alpha(\lambda=1.54184 \AA)$. The structures were solved by direct methods with the SIR97 program and refined against all F2 values with the SHELXL-97 program using the WinGX graphical user interface. All non-hydrogen atoms were refined anisotropically except as noted, and hydrogen atoms were placed in calculated positions and refined isotropically with a riding model. A summary of the crystallographic data and the structure refinement is given in Table 2.

Table 2. Crystallographic data of compound 1

\begin{tabular}{|ll|}
\hline & $\mathbf{1}$ \\
\hline Empirical formula & $\mathrm{C}_{34} \mathrm{H}_{36} \mathrm{Cl}_{2} \mathrm{Er}_{2} \mathrm{~F}_{4} \mathrm{~N}_{2} \mathrm{O}_{18} \mathrm{~S}_{6}$ \\
\hline Fw & 1434.43 \\
\hline
\end{tabular}




\begin{tabular}{|c|c|}
\hline Crystal color & red \\
\hline Crystal size $\left(\mathrm{mm}^{3}\right)$ & $0.3 * 0.2 * 0.15$ \\
\hline Temperature $(\mathrm{K})$ & 150 \\
\hline Wavelength $(\AA)$ & 1.54184 \\
\hline Crystal system, Z & Triclinic, 1 \\
\hline Space group & $P-1$ \\
\hline $\mathrm{a}(\AA)$ & $9.1849(3)$ \\
\hline $\mathrm{b}(\AA)$ & $9.7764(3)$ \\
\hline$c(\AA)$ & $14.8035(5)$ \\
\hline$\alpha\left(^{\circ}\right)$ & $103.718(3)$ \\
\hline$\beta\left(^{\circ}\right)$ & $93.278(3)$ \\
\hline$\gamma\left({ }^{\circ}\right)$ & $107.223(3)$ \\
\hline $\mathrm{V}\left(\AA^{3}\right)$ & $1221.78(7)$ \\
\hline$\rho_{\text {calc }}\left(\right.$ g.cm $\left.{ }^{-3}\right)$ & 1.950 \\
\hline$\mu(\mathrm{CuK} \alpha)\left(\mathrm{mm}^{-1}\right)$ & 10.361 \\
\hline$\theta$ range $\left(^{\circ}\right)$ & $3.102-73.339$ \\
\hline Data collected & 8501 \\
\hline Data unique & 4724 \\
\hline Data observed & 4540 \\
\hline $\mathrm{R}$ (int) & 0.0266 \\
\hline $\mathrm{Nb}$ of parameters / restraints & $334 / 15$ \\
\hline$R 1(F),{ }^{\mathrm{a}} \mathrm{I}>2 \sigma(\mathrm{I})$ & 0.0282 \\
\hline$w R 2\left(F^{2}\right),{ }^{\mathrm{b}}$ all data & 0.0717 \\
\hline$S\left(F^{2}\right){ }^{\mathrm{c}}$ all data & 1.107 \\
\hline CCDC number & 2101373 \\
\hline
\end{tabular}

4.4. Photophysical characterization. $\mathrm{Cw}$ DR of finely ground crystals of $\mathbf{1}$ was measured in hemispherical geometry using a dual-beam spectrophotometer with an integrating sphere accessory (Agilent Cary 5000 UV-vis-NIR). PL experiments were performed with the sample crystals embedded in between quartz slides, using a reflection geometry for signal collection. Ligand-centered PL was excited by an optical parametric amplifier (Light Conversion TOPAS-C) 
pumped by a regenerative Ti:sapphire amplifier (Coherent Libra-HE) (355 nm wavelength, 200 fs pulse duration, $1 \mathrm{kHz}$ pulse repetition frequency). PL detection was accomplished using a streak camera (Hamamatsu C10910) mounted on a grating spectrometer (Princeton Instruments Acton SpectraPro SP-2300), providing $\sim 30$ ps temporal resolution. Lanthanide-centered PL was photoexcited by a passively Q-switched powerchip laser (Teem Photonics PNV-M02510) (355 nm wavelength, $\sim 350 \mathrm{ps}$ pulse duration, $1 \mathrm{kHz}$ pulse repetition frequency), spectrally analyzed using a grating spectrometer (Princeton Instruments Acton SpectraPro 2300i), and measured by a NIR array detector (Andor iDus InGaAs $1.7 \mu \mathrm{m}$ ) or a NIR photomultiplier (Hamamatsu H10330A-75) interfaced to a digital oscilloscope with $1 \mathrm{GHz}$ bandwidth (Tektronix TDS 5104).

4.5. Computational Details. The Amsterdam Density Functional (ADF $)^{40-42}$ software package was used to perform partial structural optimization on the X-ray structures of the investigated complexes. Positions of the hydrogen atoms were optimized by using Kohn-Sham density functional theory (DFT), whereas the rest of the atoms were kept frozen. These calculations utilized the scalar all-electron zeroth-order regular approximation (ZORA) $)^{43}$ and the spin restricted formalism was employed by replacing the open-shell $\mathrm{Er}^{\mathrm{III}}$ and $\mathrm{Yb}^{\mathrm{III}}$ ions by closed-shell $\mathrm{Y}(\mathrm{III})$ ones. The hybrid functional PBE $0^{44,45}$ (Perdew-Burke-Ernzerhof) with $25 \%$ of exact exchange was employed along with the triple- $\zeta$ polarized Slater-type orbital (STO) all-electron basis set with one set of polarization functions for all atoms (TZP) ${ }^{46}$.

The multi-reference WFT calculations were performed with the help of the OpenMolcas software packages ${ }^{47}$ on the model compounds shown in Figure 3. In these calculations, the restricted active space self-consistent field ${ }^{48}$ (RASSCF) approach was used to treat the static correlation effects. The second-order Douglas-Kroll-Hess ${ }^{49-52}$ scalar relativistic (SR) Hamiltonian was used to treat the scalar relativistic effects in combination with the all-electron atomic natural orbital 
relativistically contracted (ANO-RCC) basis set from the Molcas library. ${ }^{53-55}$ The basis sets were contracted to the triple- $\zeta$ plus polarization (TZP) quality for the $\mathrm{Er}, \mathrm{Yb}$, and the $\mathrm{O}$ atoms coordinated to the lanthanide center $(E r, Y b=25 \mathrm{~s} 22 \mathrm{p} 15 \mathrm{~d} 11 \mathrm{f} 4 \mathrm{~g} 2 \mathrm{~h} / 8 \mathrm{~s} 7 \mathrm{p} 4 \mathrm{~d} 3 \mathrm{f} 2 \mathrm{~g} 1 \mathrm{~h} ; \quad \mathrm{O}=$ $14 \mathrm{~s} 9 \mathrm{p} 5 \mathrm{~d} 3 \mathrm{f} 2 \mathrm{~g} / 4 \mathrm{~s} 3 \mathrm{p} 2 \mathrm{~d} 1 \mathrm{f}$ ), to the double- $\zeta$ plus polarization (DZP) quality for the $\mathrm{C}, \mathrm{N}, \mathrm{O}, \mathrm{F}, \mathrm{S}$ and $\mathrm{Cl}$ atoms $(\mathrm{C}, \mathrm{N}, \mathrm{O}, \mathrm{F}=14 \mathrm{~s} 9 \mathrm{p} 4 \mathrm{~d} 3 \mathrm{f} 2 \mathrm{~g} / 3 \mathrm{~s} 2 \mathrm{p} 1 \mathrm{~d} ; \mathrm{S}, \mathrm{Cl}=17 \mathrm{~s} 12 \mathrm{p} 5 \mathrm{~d} 4 \mathrm{f} 2 \mathrm{~g} / 4 \mathrm{~s} 3 \mathrm{p} 1 \mathrm{~d})$ and to the double- $\zeta$ (DZ) quality for the $\mathrm{H}$ atoms $(\mathrm{H}=8 \mathrm{~s} 4 \mathrm{p} 3 \mathrm{~d} 1 \mathrm{f} / 2 \mathrm{~s})$. Additionally, three surrounding $\mathrm{Ln}^{\mathrm{III}}$ ions (Er ${ }^{\mathrm{III}}$ or $\mathrm{Yb}^{\mathrm{III}}$ ) were described by zero electron charged ab-initio model potentials (AIMP). ${ }^{56}$

$\operatorname{In}\left[\mathbf{Y b}(\mathbf{C I C N A n})_{3}\right]^{3-}$, the calculations were performed with a RAS $[19,1,1,3,7,3] \mathrm{SCF}$ active space. This RASSCF calculation was done on top of a CAS $(13,7) \mathrm{SCF}$ wave-function used to model the static correlation arising from the $4 \mathrm{f}^{13} \mathrm{Yb}^{\mathrm{III}}$ ion. The RASSCF calculation was allowed to create (i) one hole in the RAS1 space containing a doubly occupied bonding molecular orbital centered on the anilate ligands, and (ii) one particle in the RAS3 space containing an unoccupied anti-bonding molecular orbital on the ligand (see Figure S2). The calculations employed the state-averaged formalism at the SR level by taking into account 13 quartets spin states corresponding to the combinations of triplet spin states centered on the ligand fragment $\left(\pi-\pi^{*}\right)^{3}$ and the doublet spin states of the $\mathrm{Yb}^{\mathrm{III}}$ ion $\left({ }^{2} \mathrm{~F}\right)$. Additionally, 24 doublet spin states were also considered that correspond to the combinations of singlet spin states of the anilate ligands $\left(\pi-\pi^{*}\right)^{1}$ and the ${ }^{2} \mathrm{~F}$ doublet spin states of the metal center. $\operatorname{In}\left[\operatorname{Er}(\mathbf{C I C N A n})_{3}\right]^{3-}$, the calculations were performed with a RAS[17,1,1,3,7,3]SCF active space on top of a CAS(11,7)SCF wave-function used to model the static correlation arising from the $4 \mathrm{f}^{11} \mathrm{Er}^{\mathrm{III}}$ ion. The state-average SR calculations were performed by taking into account 16 sextet spin states corresponding to the combinations of triplet spin states centered on the ligand fragment $\left(\pi-\pi^{*}\right)^{3}$ and the quartet spin states of the $\mathrm{Er}{ }^{\mathrm{III}}$ ion $\left({ }^{4} \mathrm{I}\right)$. Additionally, 41 quartet and 112 doublet spin states were also considered that correspond to the combinations 
of singlet spin states of the anilate ligands $\left(\pi-\pi^{*}\right)^{1}$ and the quartet and doublet spin states of the metal center. In $\left[\operatorname{Er}(\mathbf{C I C N A n})_{2}\left(\mathbf{F}_{4} \mathbf{B D C}\right)\right]^{3-}$, the calculations were performed with a RAS $[15,1,1,2,7,2] \mathrm{SCF}$ active space on top of a CAS(11,7)SCF wave-function used to model the static correlation arising from the $4 \mathrm{f}^{11} \mathrm{Er}^{\mathrm{III}}$ ion. Only two bonding and two antibonding orbitals centered on the anilate ligands were added in the RAS1 and RAS3 space, respectively (see Figure S4). The state-average SR calculations were performed by taking into account 26 sextet, 41 quartet and 112 doublet spin states.

The spin-orbit coupling (SOC) was then introduced within a state interaction among the basis of calculated SR states using the restricted active space state interaction (RASSI) approach. ${ }^{56}$ Herein the SOC matrix is diagonalized using the calculated SR spin states. The nature of the molecular orbital was analyzed then using natural orbitals (NOs) that were directly obtained from the multiconfigurational wavefunctions that include SOC effects. The procedure to obtain these orbitals is explained in the References. ${ }^{57-59}$ The orbitals were then visualized with the graphical interface of the ADF software package.

\section{ASSOCIATED CONTENT}

Supporting Information. The Supporting Information is available free of charge at .... Computational figures of the three model compounds $\left[\mathrm{Yb}(\mathrm{ClCNAn})_{3}\right]^{3-},\left[\operatorname{Er}(\mathrm{ClCNAn})_{3}\right]^{3-}$, and $\left[\mathrm{Er}(\mathrm{ClCNAn})_{2}\left(\mathrm{~F}_{4} \mathrm{BDC}\right)\right]^{3-}$, and the tables containing calculated relative spin-free energies and spin-orbit energies of the ligand-centered spin states and Kramers doublet (KD) states respectively for the three compounds.

\section{Accession Codes}

CCDC 2101373 (1) contains the supplementary crystallographic data for this paper. These data can be obtained free of charge via www.ccdc.cam.ac.uk/data_request/cif, or by emailing 
data_request@ccdc.cam.ac.uk, or by contacting The Cambridge Crystallographic Data Centre, 12 Union Road, Cambridge CB2 1EZ, UK; fax: +44 1223336033.

\section{AUTHOR INFORMATION}

Corresponding Authors:

*E-mail: narcis.avarvari@univ-angers.fr. Fax: (+33)02 4173 5405. Phone: (+33)02 41735084.

*E-mail: mercuri@unica.it. Fax: (+39)0706754486. Phone: (+39)0706754486.

\section{ORCID}

Suchithra Ashoka Sahadevan : 0000-0001-7335-9549

Alexandre Abhervé: 0000-0002-3883-310X

Valentina Mameli: 0000-0002-1899-8636

Frédéric Gendron : 0000-0002-1896-3978

Boris Le Guennic: 0000-0003-3013-0546

Maria Laura Mercuri: 0000-0002-4816-427X

Narcis Avarvari: 0000-0001-9970-4494

Present Address

†SAS: Department of Applied Physical Chemistry, KTH Royal Institute of Technology, SE10044 Stockholm, Sweden

\section{Notes}

The authors declare no competing financial interest. 


\section{ACKNOWLEDGMENTS}

This work was supported in France by the CNRS, the University of Angers, and the RFI LUMOMAT network (ASCO MMM project). F.G. and B.L.G. thank the French GENCI/IDRISCINES center for high-performance computing resources and acknowledge the Stratégie d'Attractivité Durable (SAD18006-LnCPLSMM). The work in Italy was supported by the Fondazione di Sardegna - Convenzione triennale tra la Fondazione di Sardegna e gli Atenei Sardi, Regione Sardegna - L.R. 7/2007 annualità 2016 - DGR 28/21 del 17.05.2015 "Innovative Molecular Functional Materials for Environmental and Biomedical Applicatons" and INSTM. Regione Autonoma della Sardegna (RAS) is acknowledged through Delibera CIPE n. 31 del 20.02.2015 e deliberazione n. 52/36 del 28.10.2015 "Piano Strategico Sulcis" (project no. SULCIS-820947) for S. Ashoka Sahadevan's grant. CESA, Centro d'Eccellenza per la Sostenibilità Ambientale, accordo di programma RAS-UNICA-IGEA-AUSI (project number E58C16000080003) and "PON AIM (PON Ricerca e Innovazione 2014 - 2020-Azione I.2-D.D. n.407 del 27 febbraio 2018 "Attraction and International Mobility”, Cult-GeoChim project n. AIM1890410-3) are gratefully acknowledged for financing the PhD grant of M. Oggianu and the fixed-term researcher fellowship of V. Mameli, respectively. The CeSAR (Centro Servizi d'Ateneo per la Ricerca), core facility of the University of Cagliari, is acknowledged for the use of the Ultrafast Optical Spectroscopy Laboratory.

\section{REFERENCES}

(1) Rocha, J.; Carlos, L. D.; Paz, F. A. A.; Ananias, D. Luminescent Multifunctional Lanthanides-Based Metal-Organic Frameworks. Chem. Soc. Rev. 2011, 40, 926-940.

(2) Cui, Y.; Yue, Y.; Qian, G.; Chen, B. Luminescent Functional Metal-Organic Frameworks. Chem. Rev. 2012, 112, 1126-1162. 
(3) Hasegawa, Y.; Nakanishi, T. Luminescent Lanthanide Coordination Polymers for Photonic Applications. RSC Adv. 2015, 5, 338-353.

(4) Eliseeva, S. V.; Bünzli, J. C. G. Lanthanide Luminescence for Functional Materials and Bio-Sciences. Chem. Soc. Rev. 2010, 39, 189-227.

(5) Bünzli, J.-C. G.; Eliseeva, S. V. Intriguing Aspects of Lanthanide Luminescence. Chem. Sci. 2013, 4, 1939.

(6) Einkauf, J. D.; Clark, J. M.; Paulive, A.; Tanner, G. P.; De Lill, D. T. A General Model of Sensitized Luminescence in Lanthanide-Based Coordination Polymers and Metal-Organic Framework Materials. Inorg. Chem. 2017, 56, 5544-5552.

(7) Chatenever, A. R. K.; Warne, L. R.; Matsuoka, J. E.; Wang, S. J.; Reinheimer, E. W.; Lemagueres, P.; Fei, H.; Song, X.; Oliver, S. R. J. Isomorphous Lanthanide Metal-Organic Frameworks Based on Biphenyldicarboxylate: Synthesis, Structure, and Photoluminescent Properties. Cryst. Growth Des. 2019, 19, 4854-4859.

(8) Huang, J. J.; Yu, J. H.; Bai, F. Q.; Xu, J. Q. White-Light-Emitting Materials and Highly Sensitive Detection of Fe3+ and Polychlorinated Benzenes Based on Ln-Metal-Organic Frameworks. Cryst. Growth Des. 2018, 18, 5353-5364.

(9) Huang, W.; Pan, F.; Liu, Y.; Huang, S.; Li, Y.; Yong, J.; Li, Y.; Kirillov, A. M.; Wu, D. An Efficient Blue-Emissive Metal-Organic Framework (MOF) for Lanthanide-Encapsulated Multicolor and Stimuli-Responsive Luminescence. Inorg. Chem. 2017, 56, 6362-6370.

(10) Liu, L. H.; Qiu, X. T.; Wang, Y. J.; Shi, Q.; Sun, Y. Q.; Chen, Y. P. NIR Emission and Luminescent Sensing of a Lanthanide-Organic Framework with Lewis Basic Imidazole and Pyridyl Sites. Dalton Trans. 2017, 46, 12106-12113.

(11) Zhang, X.; Bing, Y.; Gao, P.; Bai, H.; Hu, M. High Sensitive Luminescent Sensing for Nitrobenzene and Iron(III) by Uncommon Ln-MOFs Containing Open Ketone Group Sites. Inorg. Chim. Acta 2017, 455, 98-104.

(12) Dang, S.; Yu, J. B.; Wang, X. F.; Guo, Z. Y.; Sun, L. N.; Deng, R. P.; Feng, J.; Fan, W. Q.; Zhang, H. J. A Study on the NIR-Luminescence Emitted from Ternary Lanthanide [Er(III), $\mathrm{Nd}(\mathrm{III})$ and $\mathrm{Yb}(\mathrm{III})$ ] Complexes Containing Fluorinated-Ligand and 4,5-Diazafluoren-9One. J. Photochem. Photobiol. A Chem. 2010, 214, 152-160.

(13) Yang, H. W.; Xu, P.; Ding, B.; Wang, X. G.; Liu, Z. Y.; Zhao, H. K.; Zhao, X. J.; Yang, E. C.; Yang, E. C. Isostructural Lanthanide Coordination Polymers with High Photoluminescent Quantum Yields by Effective Ligand Combination: Crystal Structures, Photophysical Characterizations, Biologically Relevant Molecular Sensing, and AntiCounterfeiting Ink Application. Cryst. Growth Des. 2020, 20, 7615-7625.

(14) Chen, B.; Yang, Y.; Zapata, F.; Qian, G.; Luo, Y.; Zhang, J.; Lobkovsky, E. B. Enhanced Near-Infrared-Luminescence in an Erbium Tetrafluoroterephthalate Framework. Inorg. Chem. 2006, 45, 8882-8886. 
(15) Santos, J. C. C.; Pramudya, Y.; Krstić, M.; Chen, D. H.; Neumeier, B. L.; Feldmann, C.; Wenzel, W.; Redel, E. Halogenated Terephthalic Acid "Antenna Effects" in LanthanideSURMOF Thin Films. ACS Appl. Mater. Interfaces 2020, 12, 52166-52174.

(16) Mercuri, M. L.; Congiu, F.; Concas, G.; Ashoka Sahadevan, S. Recent Advances on Anilato-Based Molecular Materials with Magnetic and/or Conducting Properties. Magnetochemistry 2017, 3, 17.

(17) Kitagawa, S. Coordination Compounds of 1,4-Dihydroxybenzoquinone and Its Homologues. Structures and Properties. Coord. Chem. Rev. 2002, 224, 11-34.

(18) Atzori, M.; Artizzu, F.; Sessini, E.; Marchiò, L.; Loche, D.; Serpe, A.; Deplano, P.; Concas, G.; Pop, F.; Avarvari, N.; Mercuri, M. L. Halogen-Bonding in a New Family of Tris(Haloanilato)Metallate(III) Magnetic Molecular Building Blocks. Dalton Trans. 2014, 43, 7006-7019.

(19) Atzori, M.; Pop, F.; Cauchy, T.; Mercuri, M. L.; Avarvari, N. Thiophene-Benzoquinones: Synthesis, Crystal Structures and Preliminary Coordination Chemistry of Derived Anilate Ligands. Org. Biomol. Chem. 2014, 12, 8752-8763.

(20) Sahadevan, S. A.; Abhervé, A.; Monni, N.; Sáenz de Pipaón, C.; Galán-Mascarós, J. R.; Waerenborgh, J. C.; Vieira, B. J. C.; Auban-Senzier, P.; Pillet, S.; Bendeif, E.-E.; Alemany, P.; Canadell, E.; Mercuri, M. L.; Avarvari, N. Conducting Anilate-Based Mixed-Valence $\mathrm{Fe}(\mathrm{II}) \mathrm{Fe}(\mathrm{III})$ Coordination Polymer: Small-Polaron Hopping Model for Oxalate-Type Fe(II)Fe(III) 2D Networks. J. Am. Chem. Soc. 2018, 140, 12611-12621.

(21) Sahadevan, S. A.; Monni, N.; Abhervé, A.; Cosquer, G.; Oggianu, M.; Ennas, G.; Yamashita, M.; Avarvari, N.; Mercuri, M. L. Dysprosium Chlorocyanoanilate-Based 2DLayered Coordination Polymers. Inorg. Chem. 2019, 58, 13988-13998.

(22) Abhervé, A.; Clemente-León, M.; Coronado, E.; Gómez-García, C. J.; Verneret, M. OneDimensional and Two-Dimensional Anilate-Based Magnets with Inserted Spin-Crossover Complexes. Inorg. Chem. 2014, 53, 12014-12026.

(23) Benmansour, S.; Abhervé, A.; Gómez-Claramunt, P.; Vallés-García, C.; Gómez-García, C. J. Nanosheets of Two-Dimensional Magnetic and Conducting Fe(II)/Fe(III) Mixed-Valence Metal-Organic Frameworks. ACS Appl. Mater. Interfaces 2017, 9, 26210-26218.

(24) Jeon, I.-R.; Negru, B.; Van Duyne, R. P.; Harris, T. D. A 2D Semiquinone RadicalContaining Microporous Magnet with Solvent-Induced Switching from T c $=26$ to $80 \mathrm{~K}$. J. Am. Chem. Soc. 2015, 137, 15699-15702.

(25) DeGayner, J. A.; Jeon, I.-R.; Sun, L.; Dincă, M.; Harris, T. D. 2D Conductive Iron-Quinoid Magnets Ordering up to $\mathrm{Tc}=105 \mathrm{~K}$ via Heterogenous Redox Chemistry. J. Am. Chem. Soc. 2017, 139, 4175-4184.

(26) Sahadevan, S. A.; Abhervé, A.; Monni, N.; Auban-Senzier, P.; Cano, J.; Lloret, F.; Julve, M.; Cui, H.; Kato, R.; Canadell, E.; Mercuri, M. L.; Avarvari, N. Magnetic Molecular Conductors Based on Bis(Ethylenedithio)Tetrathiafulvalene (BEDT-TTF) and the Tris(Chlorocyananilato)Ferrate(III) Complex. Inorg. Chem. 2019, 13, 403-411. 
(27) Ashoka Sahadevan, S.; Monni, N.; Abhervé, A.; Auban-Senzier, P.; Canadell, E.; Mercuri, M. L.; Avarvari, N. Synthesis and Physical Properties of Purely Organic BEDT-TTF-Based Conductors Containing Hetero-/Homosubstituted Cl/CN-Anilate Derivatives. Inorg. Chem. 2017, 56, 12564-12571.

(28) Atzori, M.; Pop, F.; Auban-Senzier, P.; Clérac, R.; Canadell, E.; Mercuri, M. L.; Avarvari, N. Complete Series of Chiral Paramagnetic Molecular Conductors Based on TetramethylBis(Ethylenedithio)-Tetrathiafulvalene (TM-BEDT-TTF) and Chloranilate-Bridged Heterobimetallic Honeycomb Layers. Inorg. Chem. 2015, 54, 3643-3653.

(29) Atzori, M.; Pop, F.; Auban-Senzier, P.; Gómez-García, C. J.; Canadell, E.; Artizzu, F.; Serpe, A.; Deplano, P.; Avarvari, N.; Mercuri, M. L. Structural Diversity and Physical Properties of Paramagnetic Molecular Conductors Based on Bis(Ethylenedithio)Tetrathiafulvalene (BEDT-TTF) and the Tris(Chloranilato)Ferrate(III) Complex. Inorg. Chem. 2014, 53, 7028-7039.

(30) Ashoka Sahadevan, S.; Monni, N.; Abhervé, A.; Marongiu, D.; Sarritzu, V.; Sestu, N.; Saba, M.; Mura, A.; Bongiovanni, G.; Cannas, C.; Quochi, F.; Avarvari, N.; Mercuri, M. L. Nanosheets of Two-Dimensional Neutral Coordination Polymers Based on Near-InfraredEmitting Lanthanides and a Chlorocyananilate Ligand. Chem. Mater. 2018, 30, 6575-6586.

(31) Ashoka Sahadevan, S.; Monni, N.; Oggianu, M.; Abhervé;, A.; Marongiu, D.; Saba, M.; Mura, A.; Bongiovanni, G.; Mameli, V.; Cannas, C.; Avarvari, N.; Quochi, F.; Mercuri, M. L. Heteroleptic NIR-Emitting $\mathrm{Yb}^{\mathrm{III}} /$ Anilate-Based Neutral Coordination Polymer Nanosheets for Solvent Sensing. ACS Appl. Nano Mater. 2020, 3, 94-104.

(32) Benmansour, S.; Pérez-Herráez, I.; López-Martínez, G.; Gómez-García, C. J. SolventModulated Structures in Anilato-Based 2D Coordination Polymers. Polyhedron 2017, 135, $17-25$.

(33) Atzori, M.; Artizzu, F.; Marchiò, L.; Loche, D.; Caneschi, A.; Serpe, A.; Deplano, P.; Avarvari, N.; Mercuri, M. L. Switching-on Luminescence in Anilate-Based Molecular Materials. Dalton Trans. 2015, 44, 15786-15802.

(34) Zheng, Z.; Lu, H.; Wang, Y.; Bao, H.; Li, Z. J.; Xiao, G. P.; Lin, J.; Qian, Y.; Wang, J. Q. Tuning of the Network Dimensionality and Photoluminescent Properties in Homo- And Heteroleptic Lanthanide Coordination Polymers. Inorg. Chem. 2021, 60, 1359-1366.

(35) Jin, G. Q.; Ning, Y.; Geng, J. X.; Jiang, Z. F.; Wang, Y.; Zhang, J. L. Joining the Journey to near Infrared (NIR) Imaging: The Emerging Role of Lanthanides in the Designing of Molecular Probes. Inorg. Chem. Front. 2020, 7, 289-299.

(36) Yu, H. H.; Li, J.; Yang, Y.; Li, X.; Su, Z. M.; Sun, J. Near-Infrared (NIR-II) Luminescence for the Detection of Cyclotetramethylene Tetranitramine Based on Stable Nd-MOF. J. Solid State Chem. 2021, 294, 121789.

(37) Gómez-Claramunt, P.; Benmansour, S.; Hernández-Paredes, A.; Cerezo-Navarrete, C.; Rodríguez-Fernández, C.; Canet-Ferrer, J.; Cantarero, A.; Gómez-García, C. J. Tuning the 
Structure and Properties of Lanthanoid Coordination Polymers with an Asymmetric Anilato Ligand. Magnetochemistry 2018, 4, 6.

(38) Li, M. ; Gul, S.; Tian, D.; Zhou, E.; Wang, Y.; Han, Y.; Yin, L.; Huang, L. Erbium(III)Based Metal-Organic Frameworks with Tunable Upconversion Emissions. Dalton Trans. 2018, 47, 12868-12872.

(39) Zhang, X., Li; B., Ma; H., Zhang, L.; Zhao, H. Metal-Organic Frameworks Modulated by Doping $\mathrm{Er}^{3+}$ for Up-conversion Luminescence. ACS Appl. Mater. Interfaces 2016, 8 , 17389-17394.

(40) te Velde, G.; Bickelhaupt, F. M.; Baerends, E. J.; van Gisbergen, S. J. A.; Fonseca Guerra, C.; Snijders, J. G.; Ziegler, T. Chemistry with ADF. J. Comput. Chem. 2001, 22, 931-967.

(41) Fonseca Guerra, C.; Snijders, J. G.; te Velde, G.; Baerends, E. J. Towards an Order-N DFT Method. Theor. Chem. Acc. 1998, 99, 391.

(42) Baerends, E. J.; Ziegler, T.; Atkins, A. J.; Autschbach, J.; Bashford, D.; Baseggio, O.; Bérces, A.; Bickelhaupt, F. M.; Bo, C.; Boerritger, P. M.; Cavallo, L.; Daul, C.; Chong, D. P.; Chulhai, D. V.; Deng, L.; Dickson, R. M.; Dieterich, J. M.; Ellis, D., A. L. ADF2017, SCM, Theoretical Chemistry; Vrije Universiteit, Amsterdam, The Netherlands, 2017.

(43) van Lenthe, E.; Baerends, E. J.; Snijders, J. G. Relativistic Regular Two-Component Hamiltonians. J. Chem. Phys 1993, 99, 4597-4610.

(44) Adamo, C.; Barone, V. Toward Reliable Density Functional Methods without Adjustable Paramaters: The PBE0 Model. J. Chem. Phys. 1999, 110, 6158-6170.

(45) Ernzerhof, M.; Scuseria, G. E. Assessment of the Perdew-Burke-Ernzerhof ExchangeCorrelation Funtional. J. Chem. Phys. 1999, 110, 5029-5036.

(46) van Lenthe, E.; Baerends, E. J. Optimized Slater-Type Basis Sets for the Elements $1-118$. J. Comput. Chem. 2003, 24, 1142-1156.

(47) Fdez. Galván, I.; Vacher, M.; Alavi, A.; Angeli, C.; Aquilante, F.; Autschbach, J.; Bao, J. J.; Bokarev, S. I.; Bogdanov, N. A.; Carlson, R. K.; Chibotaru, L. F.; Creutzberg, J.; Dattani, N.; Delcey, M. G.; Dong, S. S.; Dreuw, A.; Freitag, L.; Frutos, L. , R. OpenMolcas: From Source Code to Insight. J. Chem. Theory Comput. 2019, 15, 5925-5964.

(48) Roos, B. O.; Taylor, P. R.; Siegbahn, P. E. M. A Complete Active Space SCF Method (CASSCF) Using a Density Matrix Formulated Super-CI Approach. Chem. Phys. 1980, 48, $157-173$.

(49) Douglas, M.; Kroll, N. M. Quantum Electrodynamical Corrections to the Fine Structure of Helium. Ann. Phys. 1974, 82, 89-155.

(50) Hess, B. A. Applicability of the No-Pair Equation with Free-Particle Projection Operators to Atomic and Molecular Structure Calculations. Phys. Rev. A 1985, 32, 756-763. 
(51) Hess, B. A. Relativistic Electronic-Structure Calculations Employing a Two-Component No-Pair Formalism with External-Field Projection Operators. Phys. Rev. A 1986, 33, 37423748.

(52) Wolf, A.; Reiher, M.; Hess, B. A. The Generalized Douglas-Kroll Transformation. J. Chem. Phys. 2002, 117, 9215-9226.

(53) Widmark, P.-O.; Malmqvist, P.-Å.; Roos, B. O. Density-Matrix Averaged Atomic Natural Orbital (ANO) Basis-Sets for Correlated Molecular Wave-Functions. I. First Row Atoms. Theor. Chim. Acta 1990, 77, 291-306.

(54) Roos, B. O.; Lindh, R.; Malmqvist, P.-Å.; Veryazov, V.; Widmark, P.-O. Main Group Atoms and Dimers Studied with a New Relativistic ANO Basis Set. J. Phys. Chem. A 2004, $108,2851-2858$.

(55) Roos, B. O.; Lindh, R.; Malmqvist, P.-Å.; Veryazov, V.; Widmark, P.-O. New Relativistic ANO Basis Sets for Transition Metal Atoms. J. Phys. Chem. A 2005, 109, 6575.

(56) Malmqvist, P.-A.; Roos, B. O.; Schimmelpfennig, B. The Restricted Active Space (RAS) State Interaction Approach with Spin-Orbit Coupling. Chem. Phys. Lett. 2002, 357, 230240 .

(57) Gendron, F.; Páez-Hernández, D.; Notter, F.-P.; Pritchard, B.; Bolvin, H.; Autschbach, J. Magnetic Properties and Electronic Structure of Neptunyl(VI) Complexes: Wavefunctions, Orbitals, and Crystal-Field Models. Chem. Eur. J. 2014, 20, 7994-8011.

(58) Gendron, F.; Pritchard, B.; Bolvin, H.; Autschbach, J. Single-Ion 4f Element Magnetism: An Ab-Initio Look at Ln(COT)2-. Dalton Trans. 2015, 44, 19886- 19900.

(59) Autschbach, J. Orbitals for Analyzing Bonding and Magnetism of Heavy-Metal Complexes. Comments Inorg. Chem. 2016, 36, 215-244. 


\section{Table of Contents Entry}

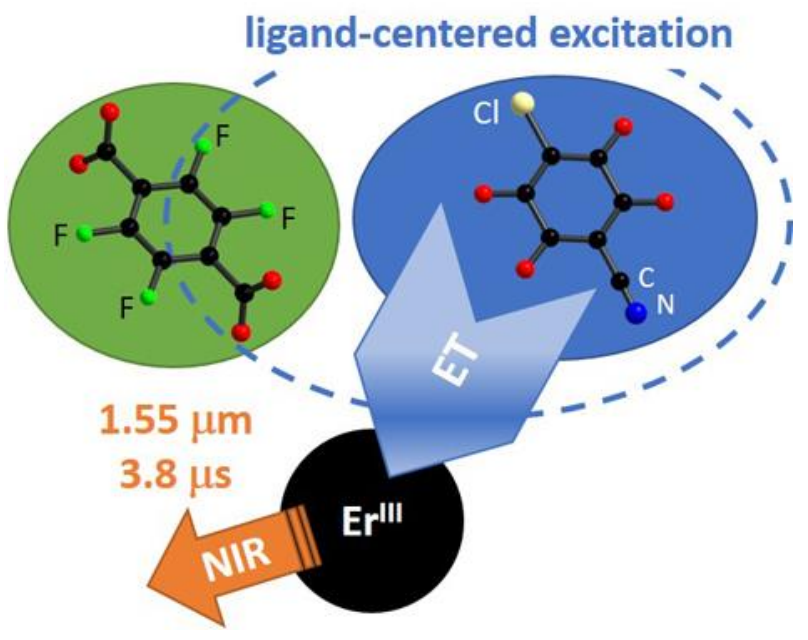

Efficient sensitization through antenna effect is demonstrated by photophysical and theoretical investigations of the NIR emissive $\mathrm{Er}^{\mathrm{III}}$-based heteroleptic $2 \mathrm{D}$ coordination polymer, prepared by the use of chlorocyanoanilate and tetrafluoro-benzene-dicarboxylate linkers. 